\title{
The Blockchain That Was Not: The Case of Four Cooperative Agroecological Supermarkets
}

\begin{abstract}
Marc Rocas-Royo *
Digital Commons Research Group, Internet Interdisciplinary Institute (IN3), Universitat Oberta de Catalunya (UOC), Castelldefels, Spain

Blockchain is a technology with many applications derived from its properties. This article analyzes the case of 4 cooperative agroecological supermarkets and in what circumstances blockchain is an exciting technology to adopt. The analysis of the gathered data reveals 10 factors to consider, 5 internal and 5 external. Those factors derive into 6 blockchain domains to develop. The article concludes that in 3 of them, the drawbacks of implementing the technology, although it is theoretically appropriate, are insuperable. The article contributes to demystifying blockchain technology and applying the same business logic we use with other technical options.
\end{abstract}

Keywords: blockchain, agro-food cooperatives, food supply chain, cooperativism, provenance

\section{OPEN ACCESS}

Edited by:

Alicia Noel,

Cultivati Inc., United States

Reviewed by:

Emmanuelle Suzanne Bourgois, Fairagora Asia and Verifik8, Singapore

Larry C. Bates,

AltMarket, United States

*Correspondence:

Marc Rocas-Royo

mrocasr@uoc.edu

Specialty section:

This article was submitted to

Blockchain for Good,

a section of the journal

Frontiers in Blockchain

Received: 01 November 2020

Accepted: 30 March 2021

Published: 28 April 2021

Citation:

Rocas-Royo M (2021) The Blockchain That Was Not: The Case of Four

Cooperative

Agroecological Supermarkets.

Front. Blockchain 4:624810.

doi: $10.3389 /$ fbloc.2021.624810

\section{INTRODUCTION}

"Food Coop" is a French-American documentary filmed by Tom Boothe in 2016. It describes how the Park Slope Food Coop (PSFC) works. The Park Slope Food Coop is a member-owned and operated food store founded in 1973 and located in the Brooklyn neighborhood in New York, United States of America. The PSFC defines itself as an alternative to profit-oriented businesses. A community of organic food supporters integrates the coop. The food store only sells to its members, and they contribute with their time, up to $2 \mathrm{~h} 45 \mathrm{~min}$ per month, to daily tasks for its maintenance. The PSFC supports nontoxic, organic agriculture and tries to avoid selling processed products.

Some organizations supporting the social economy organized showings of the film at different Catalan locations during 2018 and 2019. The film inspired the local concerned communities to imitate the PSFC initiative and create their ecological supermarket.

\section{Agroecological Cooperativism in Catalonia}

Catalonia, a region located in Southern Europe, has a long tradition of cooperativism (CoopCat, 2020). The Industrial Revolution expanded quickly in Catalonia during the 19th century. Some sectors, such as the textile industry, created many jobs, and people moved to cities that grew exponentially. Workers began developing coops to help each other cope with everyday needs, such as food provision, as many of them lacked time to purchase it.

Since the last decades of the 20th century, the increased adoption of healthier diets has allowed a new generation of food coops and associations. There are currently close to 160 agroecological consumer cooperatives in Catalonia (Espelt and Vega, 2018), with 54 of them in Barcelona (Espelt et al., 2015). It is difficult to know how many agroecological consumer groups exist because many of them adopted other legal forms, such as associations, and others simply did not adopt any. Agroecological consumer groups not only differ in the adoption of a legal entity but also in their size, motivation, the design of their organizational structure, the role of voluntary and 
mandatory work, the criteria for selecting products to sell, the relationship with producers, the feasibility of acquiring products for non-group members, the existence of a membership fee, and the involvement on social activism beyond their primary activity (Huerta and Ponce, 2010).

This article focuses on the emergence of cooperative agroecological supermarkets, a small subset of the existing agroecological consumer cooperatives.

Most of the current agroecological consumer cooperatives are buying clubs. All of the buying clubs have in common a group of family units (households with three members as average) concerned with a healthier diet. They try to consume organic seasonal products. Sometimes, they are just informal groups, although administrative problems cause them to choose a legal form, such as an association or a coop. They limit the number of family units to a number that goes from 15 to 30 . There is a basket of products to purchase from several producers. The basket usually consists of perishable products, such as fruit or vegetables. They typically establish a monthly fee to pay structure costs and a minimum periodical purchase to keep a minimum demand. They limit the number of families to be part of the organization to potentiate relationships between them and avoid a higher governance load. Once the organization succeeds in a geographical area, the demand quickly fills all the available positions, and the organization generates a waiting list. Usually, people from one or several waiting lists clone the old organization into a new one. Regarding the organization's governance, the assembly, with the one person one vote principle, adopts significant decisions. Members create work groups and permanent commissions to deal with everyday tasks. Usually, members need to donate some mandatory nonpaid time of work to the organization. The organization's members establish some criteria for choosing a new provider. They cultivate relationships with producers, try to assist them when possible, and organize visits to know each other.

Recently, the higher availability of ecological and organic products through specialized stores, especially in cities, decreased family units' interest in buying clubs. It is in this context that the "Food Coop" documentary creates its impact. Some buying club members see cooperative agroecological supermarkets as the next step in developing their social activism while consuming healthy products.

There is a crucial difference between those agroecological coops that operate as a buying club and as a cooperative agroecological supermarket: scalability. Whereas most of the Catalan studied buyers' clubs limit their membership to a maximum number of family units to minimize logistics and structure governance, a cooperative supermarket does not need to do it. The project is more robust if it has more members giving support to it. A cooperative supermarket also has a more significant cost structure as it not only needs to pay rent for the physical space. The basket of products it needs is more prominent, and so it is the catalog of suppliers. A cooperative supermarket requires higher management complexity than a buyer's club. It also can quickly scale as the marginal cost of managing a new member is close to zero. Somehow, and beyond this article's scope, we can understand cooperative supermarkets as an evolution of participating in buying clubs.

One of the major concerns for cooperative supermarkets is providing healthy and ecological products at affordable prices. Their goal is to avoid shopper's exclusion because of economic reasons. Cooperative supermarkets work for everybody having the same right to enjoy the products they offer. This goal is challenging to achieve, as ecological products are usually more expensive because of their lower production rates and the lack of economies of scale. One useful tool cooperative supermarkets have for achieving this goal has to do with supporting lower costs. When co-owners spend several hours a month carrying on daily and basic tasks, cooperative supermarkets save salaries. Some cooperative supermarkets also apply a lower and considered fairer margin than other supermarkets. The achievement of lower costs is a source of competitive advantage (Porter, 1985). A third tool for offering better prices is purchasing higher volumes of products. As it can be difficult for a single buyer, the option is centralizing orders to the same supplier. This option also has other advantages, such as the optimization of logistics and distribution, which leads to a new source of cost reduction. The work of co-owners in the supermarket requires coordinating timetables and controlling if workers follow them. Purchasing higher volumes requires establishing collaboration between several cooperative supermarkets. They can even develop a familiar brand and even offer white-label products.

Agroecological cooperativism, the umbrella term that includes all the described organizations, has a primary goal to achieve strong trust relationships between producers and consumers. They build trust through shared knowledge, transparency, and commitment. Commitment usually consists of a guarantee of a minimum amount of purchases from the buyers' side and the promise of satisfying those needs with enough products from the producer's side.

\section{Blockchain}

A blockchain is an immutable and decentralized digital ledger of transactions and recorded information. Simultaneously, it is "a giant spreadsheet for registering all assets, and a registry and inventory system for the recording, tracking, monitoring, and transacting of them" (Swan, 2015). Blockchains open the door to a new type of economy, the Internet of Value (Vigna and Casey, 2018). One of the main consequences of blockchain implementations is the decentralization of trust (Mougayar, 2016). Trust becomes an asset that the blockchain authenticates, so it is no longer necessary that the involved parties in a business transaction trust each other. Adams et al. (2017) integrated both ideas when they stated that the blockchain "reflects a true representation of 'reality' at a point in time and, in doing so, creates trust in performance between parties." That representation of reality includes the digitization of organizational behaviors. The outputs of the process are diverse. It allows the creation of decentralized autonomous organizations (DAOs) and a decentralized autonomous society (DAS) (Garrod, 2016). It also enables developing a more varied and complex economy by promoting alternative economic coordination models (Davidson et al., 2018). Finally, it 
facilitates the engineering of human interactions through algorithmic governance (Atzori and Ulieru, 2017).

\section{Content and Contribution}

This article discusses from a critical point of view how blockchain technology can help to facilitate the dynamics of cooperative agroecological supermarkets. The analysis shows all the different faces that the technology has: as a creator of value, as a costefficient enabler, as a facilitator of distributed governance, and as a provider of trust for the involved stakeholders. The article's contribution is twofold. First, it describes a new phenomenon, Catalonia's development of a new generation of cooperative agroecological supermarkets. Second, it approaches the theoretical implementation of blockchain technology to the studied case without utopian and visionary conjectures, with a critical landing, and with a sense of providing utility in front of other options.

The rest of the article is organized as follows. Section "Materials and Methods" explains the method used for approaching the studied cases. Section "Results" describes four selected case studies and shows the obtained results sorted as external and internal factors. Section "Discussion" discusses the use of blockchain technology to match the identified factors and solve detected needs. Finally, section "Conclusion" concludes the article with a summary and some final thoughts.

\section{MATERIALS AND METHODS}

Four Catalan cooperative agroecological supermarkets contributed to this article, explaining their experiences through semi-structured interviews conducted during September 2020. Complementary information came from the seminar " 3 rd edition of agroecological production and consumption," conducted online on July 22, 2020. The rest of the data belonging to each of the projects came from their websites and social networks. Both qualitative methods provided enough information for revealing several aspects that define the organizational behavior of agroecological supermarkets. The categorization of external and internal factors that shape the analysis section came from the codification of the interviews' notes. The interviews helped to create a climate of collaboration between the speakers to illustrate the significance and enthusiasm that the projects involved (Rapley, 2012). Instead, the netnography by Kozinets (2015), as information gathered from websites and social networks, gave complementary information to enrich the collected data and fill gaps.

\section{RESULTS}

\section{Case Studies}

This section presents a summary of the gathered information from the 4 cases studied. Those 4 cooperative agroecological supermarkets are El Rodal, Food Coop BCN, L'Artiga, and La Feixa. The following subsections describe each one of them.

\section{El Rodal}

El Rodal is a cooperative supermarket established in Sabadell in 2018 after its driving group met in 2017. Sabadell is a city with 200,000 inhabitants located $20 \mathrm{~km}$ to the north of Barcelona. El Rodal's members had experience in social and neighborhood groups and political activism, but none had previous experience in the food industry. "Rodal" is a Catalan word for surroundings, and it is how they call in Sabadell the fields surrounding the city. El Rodal was chosen as the name from one of the four options in a public survey. El Rodal has four governance levels: the board, work commissions, working groups, and members, which make their decisions in assembly. El Rodal has 220 members, with 150 of them paying $12.10 €$ as a monthly fee to enjoy better prices. They also produce a $50 €$ single payment as social capital and membership. El Rodal establishes a $20 \%$ margin price for fee members (subscribers) and a $40 \%$ margin price for other customers. Although anyone can buy in the store, purchases from subscribers represent $90 \%$ of total sales. El Rodal explains this ratio because of the high commitment the members have. The members especially value close attention, organizational values, a sense of belonging to a reasonable cause, and transparency. El Rodal does not ask for mandatory nonpaid work, but it allows and promotes voluntary work to develop social activism. It currently hires 1.5 people. The values it defends include a commitment to nearby producers, mutual trust and loyalty, inter-cooperation, product quality, sustainability, and activism.

\section{Food Coop BCN}

Food Coop BCN is a cooperative agroecological supermarket established in Barcelona as an association in 2018 and later funded as a coop in 2019. At the time of writing, the coop was looking for premises. Nevertheless, they were identified as critical, reaching the breakeven point, set at 1,000 partners, before signing a loan. In March 2018, close to 200 people watched the "Food Coop" documentary, and 30 people started the project. They did not know each other, and they did not have previous experience in the food sector. They had a diversity of motivations, from minimizing waste to promoting multiculturality and promoting a healthier diet with local food from organic farming. Food Coop BCN is a nonprofit entity, and it has the purpose of reinvesting any future profit. It works organized in commissions and working groups. Commissions are for permanent tasks, and working groups are more related to a specific project. The organization does not have paid workers yet, but it plans to have them in the future for management tasks. The 3 hours that each member must contribute every 4 weeks will cover the supermarket's daily work. Since the documentary's screening, other projects were inspired by them, such as La Louve (Paris, France), La Cagette (Montpellier, France), Bees Coop (Brussels, Belgium), Landare (Pamplona, Spain), Labore (Bilbao, Spain), Bio Alai (Vitoria-Gasteiz, Spain), and Som Alimentació (València, Spain). Food Coop BCN establishes two membership categories: consumer and collaborating partner. They both fund the coop with $90 €$-refundable when they leave. Anyone entering the supermarket needs to become a 
member to buy inside. There are no restrictions on becoming a new member. On the other side, Food Coop BCN wants to cover all its members' purchasing needs, including all types of products.

\section{L'Artiga}

In Catalan, "artiga" means "a piece of land, formerly covered with forest, prepared for cultivation." L'Artiga is a cooperative agroecological supermarket established in Olot, a town with 34,000 inhabitants located $110 \mathrm{~km}$ to the north of Barcelona. Like other initiatives, L'Artiga began after 70 people went to the event "Conscious and Agroecological Consumption, what options do we have?" Fifteen of them decided to create L'Artiga. They had previous experience in buying groups and cooperative movements, and the group included a couple of producers. Their primary motivations are spreading their ideas, scalability, creating social impact in their environment, and becoming a tool for transforming how people buy food.

\section{La Feixa}

"La Feixa" means "a piece of farmland in the shape of a terrace, built with dry stone margins on the mountain slopes." La Feixa is a cooperative agroecological supermarket established in Mataró, a town with 125,000 inhabitants located $30 \mathrm{~km}$ to the northeast of Barcelona. They found the coop in December 2019, and they already have more than 200 members; most of them committed to work monthly for one and a half hours in the supermarket. La Feixa offers 3 memberships for individuals and 1 for companies. An individual member pays $50 €$ as social capital and can choose to work in the supermarket one and a half hours per month and enjoy the member's price (a $10 \%$ discount) on all the articles or pay a $5 €$ monthly fee instead of working, and buy at the member's special deal. The third type of individual membership involves the $50 €$ one-time payment, which consists of the right to participate in the assembly and vote, no obligation to work, and no monthly fee to pay. This membership involves paying the same price for products as nonmembers. Anyone can buy at La Feixa, even nonmembers. The supermarket has close to 150 members and plans to offer all types of food and cleaning products. At the time of writing, La Feixa just opened its store. La Feixa has the aim to be inclusive and accessible to all types of customers. This motivation will stratify products into two layers: high-quality products and more affordable second ones. Products will have displayed handwritten information about their origin, including information about the producer. La Feixa will hire 2 people to work for $30 \mathrm{~h}$ per week to run the supermarket and coordinate the member's work. The coop has commissions that they call circles to distribute tasks and projects to develop. Close to $15 \%$ of the members participate in at least one of the circles. La Feixa uses Odoo as ERP software. Odoo is open-source software licensed under the GNU LGPLv3, including ERP, billing, accounting, and e-commerce. Because of their lack of technical expertise, they collaborate with Coodevs to implement their solution: a coop that provides technological solutions for the social economy.

\section{Analysis}

Agroecological supermarkets are organizations that are in contact with 3 main stakeholders. Those stakeholders are food producers, consumers, and other agroecological supermarkets. The 4 studied cases reveal several aspects that define the organizational behavior of agroecological supermarkets. Some of these aspects are internal to the organization, whereas others are external.

\section{External Factors}

The external identified factors, linked with the previously listed stakeholders, are the conventional type of relationships with producers, the kind of information to display to consumers, the model of cooperation with other agroecological supermarkets, the desire to create an impact on the society, and the vision about competition in the local food sector.

\section{Relationships With Food Producers}

All the studied cases look to establish a one-to-one and personal relationship with their producers. They defend prioritizing the local producers over large distributors. This decision involves selling seasonal products. They assume that some products will not be available in their supermarket during some months, for example, oranges during summer, which are possible to be found in other supermarkets in Barcelona during this season, as they proceed from abroad. The studied agroecological cooperative supermarkets establish a set of criteria for selecting the producers. La Feixa analyzes their principles, size, and the value that the producer promotes, that is, cooperativism and social work. L'Artiga certifies the producers after they demonstrate that they satisfy the requirements. El Rodal has decided to develop a double set of rules: one for quality products and a different one for more affordable products that complement the shopping cart. They also agree on developing close relationships with the producers, including product demonstrations in the supermarkets and cooperative members' visits to the producer's facilities. Food Coop BCN focuses on quality, provenance, transparency, and paying a fair price to food producers. Trust, accessibility, transparency, closeness, and communication are the main traits that describe a relationship that all the studied projects describe as more human and less commercial.

\section{Information to Display to Consumers}

All the interviewed coops express the need to display information to consumers about the product's origin. La Feixa offers a full range of organic and local products, with a minimum of processing. A commission chooses the products not only so that they are as healthy as possible but also so that, at the same time, they favor a more just and respectful society. La Feixa offers, depending on the season and availability, legumes, cereals, nuts and seeds, fruit and vegetables, meat, sausages, eggs and dairy products, coffee and infusions, craft beers and wines, bread and bakery products, canned and processed vegans, appetizers, sauces, condiments, honey and chocolate, oil, personal, child, and household hygiene products. They also include products for celiacs, vegans, and people with food intolerances. La Feixa displays product information with written labels attached to the goods. El Rodal not only displays information about the products in the store but also has published videos on its website that directly link their 
products' storytelling to their producers' voices. Food Coop BCN and L'Artiga also describe the product's provenance.

Cooperative agroecological supermarkets reveal the need to explain to the final consumer the result of selecting food producers and providing quality and proximity products.

\section{Model of Cooperation With Other Agroecological Supermarkets}

When the different projects knew each other, they discovered that they had similar needs and shared the same vision. So they decided to establish a cooperative model that involves sharing best practices, satisfying joint purchases for those cases that need to meet a minimum order's size, and developing common infrastructures such as the ERP (enterprise resource planning software) to implement and use. The design of a model of cooperation allows each one of the projects to save costs. There is no competition between them because their geographical zones of influence do not overlap and they do not see competition as an essential matter.

\section{Desire to Creating an Impact on the Society}

All the studied cases share the desire to demonstrate that a different food consumption type is possible. They trust the power of word of mouth. Their coop members are the primary transmitters when they interact with other people, and they tell them how they consume and, in some cases, also work in the cooperative. In the digital sphere, they all have a website, and they are active in social media. They all have Twitter, Facebook, and Instagram accounts.

\section{The Vision About Competition in the Local Food Sector}

Barcelona, Sabadell, Mataró, and Olot, the locations for the 4 studied cases, are the Catalan cities with other options for finding agroecological products. As it happens with El Rodal and L'Artiga, some of these options are in the same neighborhood. Nevertheless, they are not worried about competition. All 4 projects consider competition as in the background. They believe that their primary asset is the community. Their members sustain the project and are loyal to its principles. Once they reach enough members to launch the project, the project's viability is assured over the calculated breakeven.

\section{Internal Factors}

The internal identified factors are the organizational governance rules, the management of member's working hours, the social care of their members, the use of open-source software, and the vision about the transparency of their activities and decisions.

\section{The Organizational Governance Rules}

Catalonia has a law that regulates the basic functioning of cooperatives since 2015 (Generalitat de Catalunya, 2020). It establishes the cooperative's governance in two central bodies: the assembly and the governing board. The assembly meets at least once per year. The governing board is in charge of the daily operations, and it is accountable to the assembly. Beyond this mandatory governance system, the studied examples develop a flat structure with spread decisions. Everybody has a voice and votes on those issues of interest. L'Artiga has decided to implement sociocracy (Christian, 2013; Owen and Buck, 2020) as their internal governance system. The rest of the cases have specific commissions in charge of different areas of the project. La Feixa calls circles to these commissions, adopting the name used in sociocratic structures.

\section{The Management of Member's Working Hours}

When writing this article, none of the projects knew how they will manage the working hours from the point of view of logistics. They all mentioned the experience of Park Slope in New York as a reference. At Food Coop BCN, all the coop members must work at the supermarket for a minimum of 3 hours every 4 weeks. At La Feixa, there are several plans. Only in 1 of them, it is mandatory to work for 90 minutes every 4 weeks. It allows not to pay the monthly fee and to enjoy a $10 \%$ discount when purchasing.

\section{The Social Care of Their Members}

The vision that all the studied cases have about their members is evident. Since all have subscribed and paid up the capital stock, their members are the owners of the company. They do not consider each other just as shareholders but as members of the same community. They make decisions together, and they meet each other at the store when working or purchasing. Naturally, they state that if any of their members have a problem, they will take care of them because they consider themselves part of the family.

\section{The Use of Open-Source Software}

All the studied cases chose open-source software when it was available, such as Jitsi for videoconferencing. As ERP, La Feixa integrates Odoo. Another cooperative company, Coopdevs, is in charge of the software implementation. Adopting an open model of technology and model improves the development of open and democratic collaborative economic models (Espelt Rodrigo, 2018; Fuster Morell and Espelt, 2018).

\section{Transparency of Their Activities and Decisions}

Transparency is essential for all the studied cases. They all share important information online, open to everybody, mainly published on their websites. L'Artiga, for example, explains in detail on its webpage what the criteria for choosing the producers are. La Feixa describes how it has obtained a loan of 46,000€ after 92 people stood guarantor for the coop.

\section{DISCUSSION}

\section{Blockchain Technology as a Solution Provider}

Blockchain technology has many faces and applications. This section addresses those of them that relate to the external and internal dimensions presented before.

\section{Provenance}

Provenance refers to providing information about the creation, chain of custody, modifications, or influences about an artifact 
(Cheney et al., 2009: 960). The studied cooperative agroecological supermarkets understand the need to provide information about the products they sell. They see this action as physically linked to the goods, for example, a written report included in the product label or linked to the providers' provided information, for example, storytelling videos on their websites. They search that information that directly comes from the provider, and they choose how to write and display it. In most cases, they have a provider's profile to score and select providers according to their established criteria. They record the collected information in local servers or cloud services such as Google Drive.

The use of blockchain technology for provenance requires a different model. Introducing blockchain in the food supply chain has many advantages, such as transparency, traceability, authenticity, and trust, but it requires digitizing the process (Köhler and Pizzol, 2020). Nevertheless, the immediate impact is that a provenance solution affects all the supply chain. All the involved partners need to agree on a standard solution, the type of data to exchange, how they collect and send data, and finally, how they write it in a commonly used blockchain (Montecchi et al., 2019). It requires the interaction of many actors and assuring that the generated and recorded data are accurate. One possible option is the use and implementation of decentralized and consensusbased oracles, that is, external systems that provide accurate information from the real world and connect the physical and digital worlds (Kamilaris et al., 2019).

Blockchain technology is still an immature and new technology (Kamilaris et al., 2019; Kshetri, 2019; Chen et al., 2020). The food sector suffers a lack of technical capacitation for implementing blockchain projects. It is even more significant in the case of small producers and coops created from the common interest of a group of very aware consumers. The solution consists of externalizing the activity, which involves choosing a standard technology provider; that option consists of falling into a cost and analyzing if it is worthy (Kim et al., 2018). It also presumably means that the used blockchain is permissioned and centralized, diminishing the solution's net value vs. storing data in a traditional database (Garrard and Fielke, 2020).

One additional consideration refers to the type of recorded information. If the displayed information refers to some producer characteristics, such as location, production method, or the possession of a quality certificate, there is no need for using blockchain. If the information refers to specific and oracleoriginated data on a batch of products, the utility of that information vanishes at the same time the product perishes.

Finally, we need to consider that the main reason for using blockchain by the food supply chain is increasing trust (Köhler and Pizzol, 2020). In the specific case of cooperative agroecological supermarkets, the consumer's trust level is already very high. Consumers are usually coop members. So they not only have trust in the project but also make decisions on it through commissions and the assembly. It is doubtful if there is a need for increasing trust, especially when it involves an economic cost.

\section{Supply Chain}

The use of blockchain technologies allows going beyond the current limitations of food supply chain management as it provides better transparency and security of supply chains (Swan, 2015; Duan et al., 2020). Nevertheless, blockchain technologies in the food supply chain are still in an early adoption stage (Chen et al., 2020). The technology's immaturity allows only big firms in the food supply chain to implement blockchain-based solutions (Kshetri, 2019). In addition to that, only digitized supply chains are candidates for implementation (Bumblauskas et al., 2020; Rogerson and Parry, 2020).

Several authors detect barriers and challenges to solve the adoption of blockchain technology in the food supply chain. Some of the detected issues are technology difficulties (Duan et al., 2020), the lack of expertize by small organizations (Kamilaris et al., 2019), and the absence of regulations (Kamilaris et al., 2019; Chen et al., 2020; Duan et al., 2020).

Chen et al. (2020) searched for news articles and research studies that satisfy the search condition "Food supply chain" and "blockchain" published during the period 2009-2019, and identified 2,595 news articles and 115 research articles. They summarize the content into 3 thematic areas: procedures, benefits, and challenges. Regarding procedures, the pieces show 2 main themes: information collection on food supply chain and chain-style storage mechanisms. Regarding the benefits of applying blockchain technology into the food supply chain, the authors identify 5 main benefits: enhanced efficiency, quick and accurate traceability, reliability and transparency, improved food quality management, and benefit all the stakeholders in the value chain. Finally, regarding challenges, they identify 5 of them: the complexity of integration, immature application of blockchain technology, blockchain technology characteristics, high investment in blockchain-based systems, and absence of regulations, legislation, and global standard. Behnke and Janssen (2020) detected one additional challenge: organizations in the food supply chain are often reluctant to share traceability information.

Although the number of implementations is still scarce, Shahid et al. (2020) developed a complete end-to-end solution for the agriculture and food supply chain. The solution uses smart contracts over Ethereum (Buterin, 2016) and the Interplanetary File Storage System (IPFS) (Benet, 2014). The suggested system provides an efficient, secure, and trusted environment for the supply chain activities. It implements a traceability scheme, a reputation system, and an autonomous transaction system. Its main properties are accountability, credibility, autonomy, and authenticity. Alternatively, Bumblauskas et al. (2020) described the tracking of eggs from farm to consumer. The Catalan company Montsoliu also offers information to consumers about the eggs they produce (Vottun 2020). Although it helps demonstrate the origin of the eggs, it already has an official certification that offers the same trust level. Although the implementation increases brand awareness and links it to product innovation, Montsoliu does not notice that the performance has positive effects on sales. 
In the specific case of cooperative agroecological supermarkets, although the benefits of a blockchain implementation are real, 2 main barriers seem insurmountable. The first one is the investment to develop. It is clearly beyond the economic possibilities of each one of those small ventures. The only way to overcome this obstacle is through the cooperation of the whole supply chain. Producers and supermarkets need to share costs for the common infrastructure that they will use together anyway. The second one is the lack of digitization in the supply chain, which heads toward a manual introduction of information. It involves the risk of manipulation (Montegut-Salla et al., 2013) and neutralizes the potential utility of blockchain-based solutions.

\section{Security, Transparency, and Trust}

Bertino et al. (2019a) defined transparency as "the ability of a subject to effectively gain access to all information related to data used in processes and decisions that affect the subject." All the studied cases value transparency as a rooted working condition, one of the cooperative organization's fundamental pillars. Blockchain is a suitable technology for assuring transparency for three reasons (Bertino et al., 2019b). First, data transparency involves actors who need not trust each other necessarily as blockchain provides the required layer of trust. Second, blockchain satisfies the required auditing needs for data transparency, assuring access, thanks to its decentralized nature. Third, blockchain guarantees the records' protection against tampering, thanks to the immutability of data. The properties of blockchain are not only useful for organizational transparency but also for the product. Blockchain promotes trust and transparency in the food industry due to the lack of a single point of failure, the immutability of written data, the need for a consensus protocol, and the opportunity to implement truly democratic governance mechanisms (Yiannas, 2018).

In the specific case of cooperative agroecological supermarkets, the blockchain implementation would help to develop the degree of transparency that those organizations need and support.

\section{Networked Collaboration}

The studied cooperative agroecological supermarkets show a will to create links with those that share the same interests. There are two types of those community links. The first one tries to make a united community between its members that develops the cooperative's goals. The second one tries to spread a culture of conscious and ecological food consumption as a marketing tool for attracting new members. Both links need the promotion of trust and reputation, two of the characteristics that a blockchain-based system inherently has. Trust increases by replacing the need for a third party with a public ledger that increases transparency and a decentralized network that supplies robustness (Nair and Sutter, 2018). Smart contracts are the building blocks of promoting trust through linking achievements and payments and eliminating uncertainty (Reinsberg, 2020). They also allow implementing a reputation system that rewards participants who benefit the community (Xu et al., 2018).
Although blockchain can help increase the collaboration of cooperative members and monitor their performance by implementing a reputation system, there are at least 2 main drawbacks. The first one is the sense of community, linked nowadays to a physical presence. The group probably is reluctant to move toward virtuality. The second one is the possible social lack of acceptance for a reputation system. Its users would perceive it as a tool for control, undermining the primary purpose of creating a community.

\section{Sociocracy}

All the studied cooperative agroecological supermarkets share the wish for a decentralized, participative, and flat decision-making process, and the implementation of communication processes that promote transparency. L'Artiga implements sociocracy (Endenburg and Bowden, 1988; Romme, 1995) as a governance model. La Feixa uses the term "circles," the basic unit in governance systems such as holacracy (Robertson, 2015) and sociocracy because it sounds better than commissions.

Sociocracy is a shared governance model that ensures distributed power while keeping everyone's influence and agency (Rau and Koch-Gonzalez, 2018). Some of its principles are equivalence (everybody counts), distributed leadership, transparency, an omnidirectional flow of information, feedback-rich environments, and effectiveness. Pappalardo and Debizet (2020) stated that sociocracy challenges a representative democracy's assumptions through shared interlocking circles that promote a process of decision-making by consent. Sociocracy makes a distinction between the allocation of resources (governance) and day-to-day activities (operations) (Karjalainen, 2020); that distinction empowers participants to debate and discuss to make group decisions while keeping their autonomy.

It is challenging to find blockchain-based tools that help sociocratic organizations to manage their daily activity. Although they have not been explicitly designed for sociocracy, Aragon (Dhillon et al., 2017) and Vocdoni (Akasha Hub Barcelona, 2020) implement solutions that may help run sociocratic organizations. Ribas Hortal and Bromberg (2018) proposed a blockchain-based reputation layer that complements the implementation of Sociocracy 3.0 (Priest and Bockelbrink, 2017). It would allow citizens to participate in collective decision-making processes.

A scenario that combines sociocracy and blockchain fits with the vision and realities that define the context of the studied cooperative agroecological supermarkets. Sociocracy aligns with the values of those organizations. Blockchain has the potential to help to manage decision-making processes and increase trust among participants who do not know each other and physically meet from time to time.

\section{Time Bank}

Some of the studied cooperative agroecological supermarkets include its members' work as a resource for diminishing costs and creating community. Food Coop BCN's members need to donate hours of work every 4 weeks. La Feixa's members enjoy better shopping conditions if they do the same, 
although it is not mandatory for them. The management of the work time is similar to the notion of time banks. A time bank is a reciprocity system based on work, reciprocity, and respect, in which time becomes a trading currency (Cahn and Rowe, 1992). Blockchain is a useful tool for managing time banks as it is possible to implement the matching between supply-and-demand tasks using smart contracts (Lin et al., 2019; Lee et al., 2020). An implementation like this would be useful for the needs of cooperative agroecological supermarkets.

\section{CONCLUSION}

Blockchain technology undoubtedly has many applications. All of them take profit from one or several of the technology's properties. Blockchain allows creating the Internet of Value. Records become immutable. Blockchain allows running smart contracts based on oracles' information, automatically launching transactions, and transferring assets. It is possible to create reputation systems and assign rights and privileges to the ones that perform better, and sending payments almost instantaneously, no matter where we are, is almost magical. After years of visionary wishes and optimistic speculations, it is time to state that blockchain is still an immature and expensive technology not valid for all the validated theoretical purposes.

This article shows the case of cooperative agroecological supermarkets that is a small niche of the global food industry. The analysis of 4 cases identifies 5 internal factors and 5 external factors that describe the ecosystem that producers, consumers, and agroecological supermarkets shape. The external identified factors are the conventional type of relationships with food producers, the kind of information to display to consumers, the model of cooperation with other agroecological supermarkets, the desire to create an impact on the society, and the vision about competition in the local food sector. The internal identified factors are the organizational governance rules, the management of member's working hours, the social care of their members, the use of opensource software, and the vision about the transparency of their activities and decisions. Those external and internal factors and their needs map into 6 aspects of blockchain technology: provenance; supply chain automation; food transparency, security, and trust; networked collaboration; the implementation of sociocracy as a governance system; and time bank systems. Suppose that the implementation of blockchain technology satisfies those 10 internal and external factors, there is no technical reason to think, as the article shows, that blockchain cannot meet those needs. After analyzing the specific niche of cooperative agroecological supermarkets, this article shows how blockchain adoption barriers go beyond the technical side and the potential benefits this new technology provides.
Three out of the 6 studied sides of blockchain technology applied to cooperative agroecological supermarkets show significant adoption barriers. Overcoming those barriers is not a matter of technical development. Some of the obstacles are structural to the food sector, such as the need for a partner's integration, the need for modernizing an outdated industry, and the lack of digitization in the supply chain. Other hurdles are social, such as the physical and face-to-face essence of the activities involved with running a supermarket and the fear of implementing digital reputational systems that can be perceived as too controlling. Regarding those social barriers, the article also points out the perception that cooperative agroecological supermarkets do not need a technological solution for managing the trust. Finally, any new technology implementation requires an economic investment, difficult to justify for a technology that is still immature and expensive. There are no studies that quantify the return of a potential investment. The findings of this article confirm the reasoning of Hawlitschek et al. (2020). Their points are especially relevant if we consider cooperative agroecological supermarkets as part of the collaborative economy. The authors suggest 3 common misconceptions, or fallacies, on the applicability of blockchain technology. The trust fallacy defends that blockchain does not provide additional values in terms of the trust. The disintermediation fallacy notes that there is a lack of decentralized marketplaces, and the consumer will fallacy reports that there is a lack of demand from consumers for adopting the technology.

Under those circumstances, and despite the potential benefits of implementing blockchain technology for the cooperative agroecological supermarkets, sometimes, the best advice they can receive is "wait and see."

Future research needs to identify those dimensions that blockchain technology requires to develop. It is vital to match the potential implementations with the real ones and identify the policies to boost those potentialities, making them possible.

\section{DATA AVAILABILITY STATEMENT}

The original contributions presented in the study are included in the article/Supplementary Material; further inquiries can be directed to the corresponding author.

\section{AUTHOR CONTRIBUTIONS}

MR-R conceived and designed the analysis, collected the data, performed the analysis, and wrote the article.

\section{FUNDING}

The author did not receive any funding for writing this article. 


\section{REFERENCES}

Adams, R., Parry, G., Godsiff, P., and Ward, P. (2017). The Future of Money and Further Applications of the Blockchain. Strat. Change. 26 (5), 417-422. doi:10. $1002 /$ jsc. 2141

Akasha Hub Barcelona. (2020). "VOCDONI Blockchain Voting Process." ETHEREUM DEV BARCELONA, February 17, 2020. Youtube video, 50, 49. https://youtu.be/ylxnVuAjVP4.

Atzori, M., and Ulieru, M. (2017). Architecting the ESociety on Blockchain: A Provocation to Human Nature, Article (Electronic) 14, 1-21. doi:10.2139/ssrn. 2999715https://papers.ssrn.com/sol3/papers.cfm?abstract_id=2999715

Behnke, K., and Janssen, M. F. W. H. A. (2020). Boundary Conditions for Traceability in Food Supply Chains Using Blockchain Technology. Int. J. Inf. Manag. 52, 101969. doi:10.1016/j.ijinfomgt.2019.05.025

Benet, J. (2014). Ipfs-content Addressed, Versioned, P2p File System. arXiv preprint arXiv:1407.3561.

Bertino, E., Kundu, A., and Sura, Z. (2019a). Data Transparency with Blockchain and AI Ethics. J. Data Inform. Qual. 11 (4), 1-8. doi:10.1145/3312750

Bertino, E., Merrill, S., Nesen, A., and Utz, C. (2019b). Redefining Data Transparency: A Multidimensional Approach. Computer 52 (1), 16-26. doi:10.1109/mc.2018.2890190

Bumblauskas, D., Mann, A., Dugan, B., and Rittmer, J. (2020). A Blockchain Use Case in Food Distribution: Do You Know where Your Food Has Been?. Int. J. Inf. Manag. 52, 102008. doi:10.1016/j.ijinfomgt.2019.09.004

Buterin, V. (2016). "Ethereum: Platform Review." Opportunities and Challenges for Private and Consortium Blockchains. Berlin: Springer.

Cahn, E., and Rowe, J. (1992). "Time dollars." The New Currency that Enables Americans to Turn Their Hidden Resource-Time-Into Personal Security and Community Renewal. Pennsylvania: Emmaus.

Chen, S., Liu, X., Yan, J., Hu, G., and Shi, Y. (2020). Processes, Benefits, and Challenges for Adoption of Blockchain Technologies in Food Supply Chains: A Thematic Analysis. Inform. Syst. E-Business Manage. 11, 0123456789. doi:10. 1007/s10257-020-00467-3

Cheney, J., Chong, S., Foster, N., Seltzer, M., and Vansummeren, S. (2009). "Provenance: A Future History," in Proceedings of the 24th ACM SIGPLAN Conference Companion on Object-Oriented Programming Systems Languages and Applications, 957-964.

Christian, D. L. (2013). Self-governance with Circles and Double Links: How Sociocracy Can Help Communities, Part II. Communities 161, 61. doi:10.1093/ wentk/9780190946395.003.0010

CoopCat. (2020). Brief Summary of the History of Catalan Cooperativism. Available at: https://www.cooperativescatalunya.coop/index.php/ca/recursos/ rutes-cooperatives/9-observatori/9-breu-historia-del-cooperativisme-catala (Accessed October 31).

Davidson, S., De Filippi, P., and Potts, J. (2018). Blockchains and the Economic Institutions of Capitalism. J. Inst. Econ. 14 (4), 639-658. doi:10.1017/ s1744137417000200

Dhillon, V., Metcalf, D., and Hooper, M. (2017). Decentralized Organizations Blockchain Enabled Applications. Berkeley, CA: Apress, 47-66.

Duan, J., Zhang, C., Gong, Y., Brown, S., and Li, Z. (2020). A Content-analysis Based Literature Review in Blockchain Adoption within Food Supply Chain. Int. J. Environ. Res. Publ. Health. 17 (5), 114. doi:10.3390/ijerph17051784

Endenburg, G., and Bowden, C. W. (1988). Sociocracy: The Organisation of Decision-Making: "No-Objection" as the Principle of Sociocracy. Stichting Sociocratisch Centrum. 12, 33-39.

Espelt, R., Peña-López, I., Losantos, P., Rodríguez, E., Martín, T., and Pons, F. (2015). "Mapping Agro-Food Consumption Groups in the City of Barcelona," in Proceedings of the XXVI ESRS Congress. Editors M. Kohe, A. Koutsouris, R. B. Larsen, D. Maye, E. Noe, T. Oedl-Wieser, et al. (Aberdeen: The James Hutton Institute), 37.

Espelt, R., and Vega, N. (2018). Cooperativisme I Agroecologia a Barcelona. Comanegra 15, 32. doi:10.33240/rba.v15i5.23201

Espelt Rodrigo, R. (2018). Cooperatives de consum agroecològic de plataforma. El paper de les Tecnologies de la Informació i la Comunicació en el consum cooperatiu de productes agroecològics.

Fuster Morell, M., and Espelt, R. (2018). "How Much Are Digital Platforms Based on Open Collaboration? an Analysis of Technological and Knowledge Practices and Their Implications for the Platform Governance of a Sample of 100 Cases of Collaborative Digital Platforms in Barcelona," in Proceedings of the 14th International Symposium on Open Collaboration, 1-5.

Garrard, R., and Fielke, S. (2020). Blockchain for Trustworthy Provenances: A Case Study in the Australian Aquaculture Industry. Technol. Soc. 62, 101298. doi:10. 1016/j.techsoc.2020.101298

Garrod, J. Z. (2016). The Real World of the Decentralized Autonomous Society. TripleC. 14 (1), 62-77. doi:10.31269/triplec.v14i1.692

Hawlitschek, F., Notheisen, B., and Teubner, T.. A 2020 Perspective on "The Limits of Trust-free Systems: A Literature Review on Blockchain Technology and Trust in the Sharing Economy". Electron. Commer. Res. Appl. 40 (2020). 100935. doi:10.1016/j.elerap.2020.100935

Huerta, A., and Ponce, E. (2010). Els grups i les cooperatives de consum ecològic a Catalunya. Barcelona: FCCUC.

Kamilaris, A., Fonts, A., and Prenafeta-Boldú, F. X. (2019). The Rise of Blockchain Technology in Agriculture and Food Supply Chains. Trends Food Sci. Technol. 91, 640-652. doi:10.1016/j.tifs.2019.07.034

Karjalainen, R. (2020). Governance in Decentralised Networks. SSRN Electron. J. 13, 1-35. doi:10.2139/ssrn.3551099

Kim, H. M., Laskowski, M., and Nan, N. (2018). A First Step in the Coevolution of Blockchain and Ontologies: Towards Engineering an Ontology of Governance at the Blockchain Protocol Level. arXiv preprint arXiv : 1801.02027 .

Köhler, S., and Pizzol, M. (2020). Technology Assessment of Blockchain-Based Technologies in the Food Supply Chain. J. Clean. Prod. 269, 114. doi:10.1016/j. jclepro.2020.122193

Kozinets, R. V. (2015). Netnography. Int. Encycl. Digital Commun. Soc. 12, 1-8. doi:10.1002/9781118767771.wbiedcs067

Kshetri, N. (2019). Blockchain and the Economics of Food Safety. IT Prof. 21 (3), 63-66. doi:10.1109/mitp.2019.2906761

Lee, Y. T., Lin, J. J., Hsu, J. Y. J., and Wu, J. L. (2020). A Time Bank System Design on the Basis of Hyperledger Fabric Framework. IEEE International Conference on Blockchain and Cryptocurrency, ICBC 2020, 1-16. doi:10.1109/ICBC48266. 2020.9169476

Lin, Xuheng., Xu, Ronghua., Chen, Yu., and Koji Lum, J. (2019). "A Blockchain-Enabled Decentralized Time Banking for a New Social Value System," in 2019 IEEE Conference on Communications and Network Security (CNS), IEEE, 1-5.

Montecchi, M., Plangger, K., and Etter, M. (2019). It's Real, Trust Me! Establishing Supply Chain Provenance Using Blockchain. Bus. Horiz. 62 (3), 283-293. doi:10.1016/j.bushor.2019.01.008

Montegut-Salla, Y., Cristóbal-Fransi, C.-F. E., and Maria Jesús Gómez-Adillón, M. J. (2013). Understanding the Situation and Factors of ICT Adoption in Agricultural Cooperatives. J. Electron. Commer. Org. 11 (3), 1-26. doi:10. 4018/jeco.2013070101

Mougayar, W. (2016). The Business Blockchain: Promise, Practice, and Application of the Next Internet Technology. Hoboken: John Wiley \& Sons.

Nair, M., and Sutter, D. (2018). The Blockchain and Increasing Cooperative Efficacy. Indepen. Rev. 22 (4), 529. doi:10.1109/bloc.2019.8751340

Owen, R. L., and Buck, J. A. (2020). Creating the Conditions for Reflective Team Practices: Examining Sociocracy as a Self-Organizing Governance Model that Promotes Transformative Learning. Reflect. Pract. 21 (6), 786-802. doi:10.1080/ 14623943.2020.1821630

Pappalardo, M., and Debizet, G. (2020). Understanding the Governance of Innovative Energy Sharing in Multi-Dwelling Buildings through a Spatial Analysis of Consumption Practices. Global Transitions. 2, 221-229. doi:10. 1016/j.glt.2020.09.001

Porter, Michael. E. (1985). Competitive Advantage. Ashcroft: The Tree Press.

Priest, J., and Bockelbrink, B. (2017). Sociocracy 3.0. London: Sociocracy30. org, 147.

Rapley, T. (2012). The (Extra) Ordinary Practices of Qualitative Interviewing. The SAGE handbook of interview research: The complexity of the craft. Upper Saddle River: The SAGE, 541-554.

Rau, T. J., and Koch-Gonzalez, J. (2018). Many Voices One Song: Shared Power with Sociocracy. London: Sociocracy for All.

Reinsberg, B. (2020). Fully-Automated Liberalism? Blockchain Technology and International Cooperation in an Anarchic World. Int. Theory 1-27, 133. doi:10. 1017/S1752971920000305 
Ribas Hortal, A., and Bromberg, F. (2018). "Towards Self-Determinant Citizen Governance: Trust-Boosting Sociocracy 3.0 with Blockchain," in Symposium On Implementing Collaborative Governance. Models, Experiences And Challenges To Foster Policy Coordination, and to Enhance Sustainable Community Outcomes And Public Value Generation. Buenos Aires: Ced4 System Dynamic Group (Universidad de Palermo).

Robertson, B. J. (2015). Holocracy. New York: The New Management System For a Rapidly Changing World.

Rogerson, M., and Parry, G. C. (2020). Blockchain: Case Studies in Food Supply Chain Visibility. Supply Chain Manage. 25 (5), 601-614. doi:10.1108/scm-082019-0300

Romme, A. G. L. (1995). The Sociocratic Model of Organizing. Strat. Change. 4, 209-215. doi:10.1002/jsc.4240040404

Shahid, A., Almogren, A., Javaid, N., Al-Zahrani, F. A., Zuair, M., and Alam, M. (2020). Blockchain-Based Agri-Food Supply Chain: A Complete Solution. IEEE Access. 8, 69230-69243. doi:10.1109/access.2020.2986257

Swan, M. (2015). Blockchain: Blueprint for a New Economy. Sebastopol: O'Reilly Media.
Vigna, P., and Casey, M. J. (2018). The Truth Machine: The Blockchain and the Future of Everything. New York: HarperCollins Publishers.

Xu, R., Lin, X., Qi, D., and Chen, Y. (2018). Constructing Trustworthy and Safe Communities on a Blockchain-Enabled Social Credits System. ACM Int. Conf. Proc. Ser. 13, 449-453. doi:10.1145/3286978.3287022

Yiannas, F. (2018). A New Era of Food Transparency Powered by Blockchain. Innov. Technol. Govern. Glob. 12 (1/2), 46-56. doi:10.1162/inov_a_00266

Conflict of Interest: The author declares that the research was conducted in the absence of any commercial or financial relationships that could be construed as a potential conflict of interest.

Copyright (c) 2021 Rocas-Royo. This is an open-access article distributed under the terms of the Creative Commons Attribution License (CC BY). The use, distribution or reproduction in other forums is permitted, provided the original author(s) and the copyright owner(s) are credited and that the original publication in this journal is cited, in accordance with accepted academic practice. No use, distribution or reproduction is permitted which does not comply with these terms. 